precoz, conlleve una mejor respuesta terapéutica. En algunos textos clásicos se habla de recuperación tras un mes de oclusión (9), esto puede deberse a la gran riqueza de colaterales en la circulación renal, arterias renales accesorias y también por el grado de oclusión. En la revisión realizada por Gasparini (4) se valora el grado de oclusión y la tasa de recuperación renal concluyendo que en caso de oclusión completa este es del 66\% y sí es parcial de un $86 \%$. Blakely y cols. (6) describen una oclusión incompleta de 28 días de evolución que recupero la función renal tras fibrinolisis. Fort y cols. (7) intentaron revascularizar una oclusión completa de 5 días de evolución y aunque no recupero completamente la función renal si que mejoro lo suficiente como para no necesitar diálisis. Un matiz añadido en caso de oclusión completa, es que en riñones con arterias renales muy estenóticas por arteriosclerosis la supervivencia renal esta muy aumentada, con mayor resistencia a la isquemia al haber una circulación colateral muy desarrollada, describiéndose casos de recuperación de la función renal tras 47 días de oclusión de la arteria renal principal (5).

La fibrilación auricular es la causa más frecuente de embolia en la arteria renal. Debe considerarse el diagnóstico en toda persona que comienza con dolor lumbar o en flanco, asociado a oligoanuria, hipertensión arterial o fiebre y con patología cardiaca de base. Una analítica con leucocitosis, elevación de transaminasas y LDH, con orina hematúrica y piúrica orientara el diagnóstico. Esta indicado realizar ecografía renal y ecodoppler de arterias renales. La arteriografía es la prueba diagnostica fundamental.

En caso de oclusión completa el tratamiento de elección es la revascularización con fibrinolisis intraarterial asociada a Heparina i.v con o sin angioplastia previa, y siempre que no halla transcurrido más de 5-7 días del inicio de los síntomas. Deberá valorarse la posibilidad de realizarla transcurrido mas de este tiempo sobre todo ante la presencia de datos de arteriosclerosis en la arteriografía y /o oclusión segmentaria de la arteria renal.

La cirugía quedaría reservada para los casos de oclusión en caso de trombosis sobre la arteria renal.

F. Blasco Patiño, J. Gómez Moreno, F. Román García, J. Martínez López de Letona, C. Moar Martínez

Servicio de Medicina Interna II. Hospital Universitario, Clínica Puerta de Hierro. Madrid

1. Praga M. Nefropatías vasculares. En Tratado de Medicina Interna ed. J.Rodes Teixidor y J.Guardia Massó. Masson S.A. Barcelona. 1997; 2396-7.

2. RK Lesman, SF Johnson, JW Coburn, JJKaufman. Clinical Features and long-term Follow-up of 17 cases. Ann Intern Med 1978; 89: 477-82.

3. Mugge A, Gulba DC, Frei U, Wagenbreth Y, Grote R, Daniel WG, et al. Renal artery embolism: Trombolysis with recombinant tissue-type plasminogen activator. J Intern Med. 1990; 228: 279-86.

4. Gasparin M, Hofmann R, Stoller M. Renal Artery embolism: Clinical Features and therapeutic options. J Urol 1992; 147: 567-72.

5. Boyer L, Ravel A, Boisier A, Alexandre M, Cluzel P, Baget JC, et al. Percutaneus Recanalization of recent Renal Artery Occlusions: Report of 10 Cases. Cardiovasc Intervent Radiol 1994; 17: 258-63.

6. Bakely P, Cosby RL, McDonald BR. Nephritic urinary sediment in embolic renal infarction. Clin Nephrol 1994; 42: 401-3.

7. Fort J, Camps J, Ruiz P, Segarra A, Gómez M, Matas M, et al. Renal artery embolism successfully revascularized by surgery after 5 days anuria. Is It never too late? Nephrol Dial Transplant 1996; 11: 1843-5.

8. Skinner RE, Hefty T, Long TD, Rosch J, Forth M. Recovery of fimction in a solitary Kidney after intraarterial thrombolytic therapy. J Urol 1989; 141: 108-9.

9. Cohen JJ. Renal artery occlusion. En: Cecil Textbook of Medicine ed. W.B Saunders Company. Philadelphia. 1988; 632-3.

\section{Afectación multicéntrica en el sarcoma de Kaposi clásico agresivo}

\section{Sr. Director:}

La variante de Sarcoma de Kaposi (SK) clásico ha pasado a un segundo plano en frecuencia, desde la aparición de la epidemia de VIH, siendo esta forma la más descrita actualmente $(1,2)$. Presentamos un SK clásico, en su forma agresiva o sistemica, con invasión visceral, en el que destacamos la forma de presentación de las lesiones cutáneas en la extremidad inferior izquierda, que comenzando como máculas aisladas de coloración violácea intensa, fueron confluyendo, adoptando la forma de una placa infiltrativa extendida a dedos, dorso del pie y tercio inferior de pierna, intensificando posteriormente su coloración hasta hacerse cianotico negruzca lo que hacia confundirla con un trastorno isquemico (Fig. 1).

Este paciente de 71 años, comenzó un año antes de su diagnostico definitivo con lesiones tipo mácula violácea en el dorso del pie, a las que no dio importancia. Posteriormente fueron extendiéndose como hemos indicado, asociándose a una clínica progresiva de fiebre intermitente $\left(38-39^{\circ} \mathrm{C}\right)$ que se mantenía durante algunos días, astenia, anorexia, dolores abdominales difusos y perdida de peso. La exploración clínica mostraba constitución astenica, hepatoesplenomegalia palpable de varios traveses de dedo y la lesión descrita en pie izq. que sugería una patología isquemica, cuya duda surgía al palpar un pulso pedio normal. Su analítica no mostró ningún dato relevante, estando la VSG en 42 a la primera hora, siendo normal el hemograma, bioquímica hepática y renal, así como marcadores tumorales, inmunoglobulinas y autoanticuerpos. En las exploraciones complementarias destacaba, radiografía de tórax con patrón intersticial afectando a pulmón derecho, confluyendo en zonas que daban al mismo un aspecto parcheado que confirmaba el TAC torácico, apreciándose en este un nódulo en la zona de mamaria interna izquierda. El TAC abdominal confirmaba gran esplenomegalia, riñón izquierdo hipoplasico con infiltración que también afectaba a vasos renales anulán-

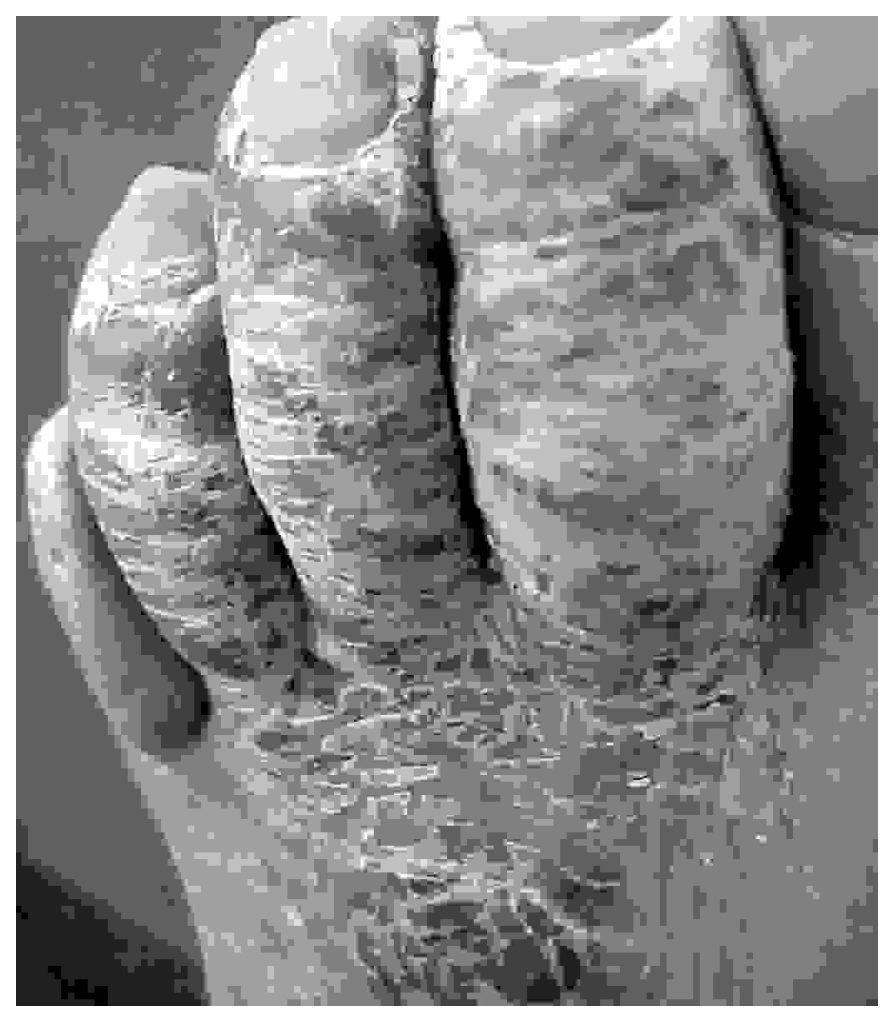

Fig. 1. Lesión infiltrativa afectando a dedos y dorso de pie izq. 
dolos, aparecían adenopatias aumentadas de tamaño retroperitoneales y paraaorticas. Se evidencio una masa en fosa inguinal izquierda envolviendo el paquete de vasos iliacos externos, aunque respetando los mismos como pudo comprobarse con ecodoppler de la zona. Se visualizo otra masa pararectal derecha.

Tras biopsiar lesiones cutáneas y hacer laparotomia se confirmo un SK por estudio anatomopatológico. Con posterioridad se realizo serologia de VIH ya que el paciente no presentaba factores de riesgo, siendo negativa.

El SK descrito en 1872 por Moritz Kohn (3) puede presentarse bajo dos formas de evolución, una benigna de localización cutánea, que suelen presentar supervivencias de mas de quince años y otra de forma agresiva o sistemica con invasión visceral, de más rara presentación, como la de este paciente, afectando a individuos entre los 50-70 años, más en la cuenca mediterránea y también en raza judía (4). Actualmente además de esta forma, se distinguen los tipos de SK africano o endémico, extendido sobre todo por el Africa Ecuatorial, el epidémico de los pacientes VIH, y los asociados a inmunodeprimidos yatrogenicamente y trasplantados.

Diferentes factores se habían descrito como posibles causantes del SK (genéticos, ambientales, hormonales, psicoestimulantes, agentes inorgánicos, infecciosos etc.), interpretándose que estos actuarían como agentes mutagénicos per se o bien alterando la inmunidad y facilitando la expresión de un agente infeccioso latente y con capacidad oncogénica (5), comprobándose actualmente que dicho agente está íntimamente asociado al virus del herpes humano tipo 8 (HHV8) $(6,7)$. La transmisión es frecuentemente por vía sexual, como se había sospechado por la epidemiología de su presentación, sin que puedan descartarse otras vías, como saliva, contacto mucoso y sanguíneo (6).

Es de gran interés la sospecha diagnostica de este proceso en nuestro medio, en pacientes sin factores de riesgo, el ser un área geográfica de mayor incidencia, llegando a producir una extensa afectación cutánea en forma de placa de color negruzco en miembros inferiores, simulando un trastorno isquémico propio de edades avanzadas como sucedía en este caso. Es muy llamativa en este enfermo la gran diseminación visceral, con afectación pulmonar y ganglionar como órganos más frecuentemente afectados según se describe en la literatura y como rara la afectación que presentaba renal y esplenica (5). Se observaban masas respetando trayectos vasculares y a nivel pararectal derecho, lo que le confiere esa característica de neoplasia multicentrica. Llama también la atención la escasa afectación analítica, solo en algunos casos de SK clásico se describe un inmunosupresión con conversión de la relación linfocitos T-helper/T-supresores. Esta descripción coincidiría con lo que indican algunos autores en cuanto a que este proceso mas que un tumor, seria una proliferación vascular diseminada en la que intervendrían sustancias circulantes mitogenicas, puestas en marcha por el proceso etimológico descrito, ello explicaría el carácter multicentrico y la pobreza de mitosis en las biopsias (8).

La supervivencia descrita escasamente supera los dos años en estas formas agresivas (5), en nuestro caso desde que comienzan las lesiones y su clínica, la supervivencia es de dieciocho meses, habiendo sido sometido en la actualidad a tratamiento oncológico con poliquimioterapia, describiéndose en la bibliografía distintos regímenes terapéuticos bien con monoquimioterapia, interferonalfa, poliquimioterapia etc., no existiendo series amplias que analicen los resultados en el SK clásico.

\section{F. J. Miras Parra, L. Muñoz Medina, A. Álvarez de Cienfuegos Rodríguez, F. J. Gómez Jiménez, I. Gazquez Pérez}

Servicio de Medicina Interna B. Hospital Clínico Universitario. Granada

1. Soriano V, Hewlett J. Etiología del Sarcoma de Kaposi. Med Clin (Barc) 1991; 96: 662-7.
2. Azón Masoliver A. El Sarcoma de Kaposi epidémico. Med Clin (Barc) 1991; 96: 614-6.

3. Kaposi M. Idipathisches multiples pigment-sarcom der haut. Arch Dermatol Syph 1872; 4: 265-73.

4. Fenig E, Brenner B, Rakowsky E, Lapidoth M, Katz A, Sulkes A. Clasic Kaposi Sarcoma. Experience at Rabin Medical Center in Israel. Am J Clin Oncol (CCT) 1998; 21: 498-500.

5. Just Sarobé M, Ribera Pibernat M, López Cabreriza P,Urrutia de Diego A, Ferrandiz Foraster C. Sarcoma de Kaposi clásico de comportamiento agresivo. Rev Clin Esp 1998; 198: 95-8.

6. Sturzl M, Ensoli B. Big but weat: How many pathogenic genes does human herpesvirus-8 need to cause Kaposi's Sarcoma Int J Oncol 1999; 14: 287-289.

7. Martin JN, Ganem ED, Osmon DH, Page-Shafer KA, Macrae D, Kedes DH. Sexual transmission and the natural history of human herpesvirus 8 infection. N Engl J Med 1998; 338: 948-954.

8. Brooks JJ. Kaposi's sarcoma: A reversible hyperplasia. Lancet 1986; 2: 1309-11.

\section{Nódulo pulmonar en paciente cirrótico}

\section{Sr. Director:}

Las varices esofágicas (VE) son múltiples colaterales venosas que rodean al esófago y comunican la vena coronaria y gástricas cortas con las venas intercostales, ácigos y hemiácigos, descomprimiendo el sistema portal (1). Se ven raramente en las radiografías $(\mathrm{Rx})$ de tórax, aún cuando son grandes, presentándose característicamente en mediastino posteroinferior. Comunicamos el caso de un paciente con hipertensión portal severa y un nódulo pulmonar en la Rx de tórax, no presente un año antes, llamando la atención sobre esta infrecuente presentación de las VE.

Varón de 64 años, con cirrosis por virus C (estadio B8 de Child Pugh) e hipertensión portal, en programa de trasplante hepático desde cuatro meses antes. Diagnóstico angiográfico de trombosis y cavernomatosis. Diagnóstico endoscópico previo de varices esofágicas grado IV y varices gástricas, sin antecedentes de sangrado, gastropatía de la hipertension portal. Hiperesplenismo. colelitiasis y diabetes mellitus. Episodios de encefalopatía y ascitis. Ingresa por clínica de dos días de fiebre y malestar abdominal. En la exploración destaca una ictericia moderada, sin signos de encefalopatía. En abdomen matidez en flancos y esplenomegalia importante. En la analítica presentaba una hemoglobina de $8,7 \mathrm{~g} / \mathrm{dl}$, leucocitos de $710 / \mathrm{mm}^{3}$, plaquetas de $12.000 / \mathrm{mm}^{3}$, tiempo de protrombina del $33 \%$, bilirrubina total de $4,3 \mathrm{~g} / \mathrm{dl}$, proteínas totales de $5,4 \mathrm{~g} / \mathrm{dl}$ y albúmina de 2,78 g/dl. Glucosa, urea, creatinina, ácido úrico, sodio, potasio, AST, ALT, FA, GGT y afetoproteína normales o negativas. Tras paracentesis se diagnosticó peritonitis bacteriana espontánea (PBE) y se instauró tratamiento con cefotaxima. La Rx de tórax PA (Fig. 1) mostró un nódulo pulmonar paracardial derecho, que no estaba presente en control previo un año antes. La proyección lateral mostró una radiodensidad tenue sobre la silueta cardíaca; el mediastino posterior estaba libre. Un TAC con contraste i.v. toracoabdominal mostró una vena ácigos agrandada, visualizándose bajo la carina traqueal y a nivel cardial imágenes serpinginosas que captaban contraste compatibles con varices esofágicas. En abdomen se hallaban alteraciones compatibles con cirrosis hepática con marcada hipertensión portal y esplenomegalia. En doppler abdominal había trombosis portal, marcadas colaterales en hilio esplénico y signos de cortocircuito esplenorrenal espontáneo; las venas mesentérica superior y esplénica estaban dilatadas. En angiografía hepática posterior se constataron estos hallazgos, con varices gastroesofágicas de gran tamaño. La evolución de la PBE fue satisfactoria. El paciente fue trasplantado nueve meses después falleciendo en el postoperatorio inmediato.

La visibilidad de las VE en la Rx de tórax de los pacientes con hipertensión portal se ha estimado en el $10 \%(4,8-8,3 \%)(2,3)$. Lee y cols. han comunicado recientemente la mayor sensibilidad 